\title{
Familial risk for lung cancer (Review)
}

\author{
MADIHA KANWAL $^{1,2}$, XIAO-JI DING $^{1}$ and YI CAO $^{1}$ \\ ${ }^{1}$ Laboratory of Molecular and Experimental Pathology, Kunming Institute of Zoology, Chinese Academy of Sciences, \\ Kunming, Yunnan 650223; ${ }^{2}$ Kunming College of Life Sciences, University of Chinese Academy of Sciences, \\ Beijing 100049, P.R. China
}

Received June 1, 2015; Accepted August 26, 2016

DOI: $10.3892 / \mathrm{ol} .2016 .5518$

\begin{abstract}
Lung cancer, which has a low survival rate, is a leading cause of cancer-associated mortality worldwide. Smoking and air pollution are the major causes of lung cancer; however, numerous studies have demonstrated that genetic factors also contribute to the development of lung cancer. A family history of lung cancer increases the risk for the disease in both smokers and never-smokers. This review focuses on familial lung cancer, in particular on the familial aggregation of lung cancer. The development of familial lung cancer involves shared environmental and genetic factors among family members. Familial lung cancer represents a good model for investigating the association between environmental and genetic factors, as well as for identifying susceptibility genes for lung cancer. In addition, studies on familial lung cancer may help to elucidate the etiology and mechanism of lung cancer, and may identify novel biomarkers for early detection and diagnosis, targeted therapy and improved prevention strategies. This review presents the aetiology and molecular biology of lung cancer and then systematically introduces and discusses several aspects of familial lung cancer, including the characteristics of familial lung cancer, population-based studies on familial lung cancer and the genetics of familial lung cancer.
\end{abstract}

\section{Contents}

1. Introduction

2. Aetiology of lung cancer

3. Molecular biology of lung cancer

4. Familial lung cancer

5. Conclusion

Correspondence to: Miss. Madiha Kanwal, Laboratory of Molecular and Experimental Pathology, Kunming Institute of Zoology, Chinese Academy of Sciences, 32 Jiaochang Donglu, Kunming, Yunnan 650223, P.R. China

E-mail: madiha_k14@hotmail.com

Key words: familial cancer, lung cancer, genetic factor, environmental factor, oncogene, tumour suppressor gene, germline mutation

\section{Introduction}

Annually, there are 7.6 million cancer-associated mortalities worldwide, of which lung cancer accounts for 1.37 million deaths (1). Lung cancer, which is also known as carcinoma of the lung or pulmonary carcinoma, and is derived from epithelial cells, is a malignant lung tumour characterised by uncontrolled cell growth in the tissues of the lung. Lung cancer is categorised into small cell lung cancer (SCLC) and non-small cell lung cancer (NSCLC). NSCLC, which constitutes $\sim 80 \%$ of all lung cancers, is further classified into adenocarcinoma, squamous cell carcinoma and large cell carcinoma (2). Early-stage lung cancer can be treated surgically with a good survival rate; however, most cases are identified in the late stages when surgery is no longer an option as a result of distant metastases (3). Elucidating the aetiology and mechanism of lung cancer is fundamental for its diagnosis, treatment and prevention.

Familial cancers, wherein multiple family members are diagnosed with the same cancer, are good models for investigating the aetiology and mechanism of cancer (1). Notably, familial lung cancer, in particular the familial aggregation (or occurrence) of lung cancer, has a high incidence, particularly in certain regions of China, such as Xuanwei City in the Yannan Province (4). The familial aggregation of lung cancer may be influenced by several factors, including genetic factors, similar lifestyles (e.g. smoking habit and diet) and similar environments (e.g. indoor and outdoor air pollution). Studies on familial lung cancers may help to elucidate the aetiology and mechanism of this disease and may reveal novel oncogenes and tumour suppressor genes.

This review systematically introduces and discusses several aspects of the familial aggregation of lung cancer, including the aetiology, molecular biology, genetics and other characteristics of familial lung cancer. Population-based studies on this disease are also discussed.

\section{Aetiology of lung cancer}

Lung cancer is one of the few cancers with a well-known aetiology (5). Smoking is the main cause of lung cancer; however, the majority of smokers do not develop lung cancer, and many patients with lung cancer have never smoked (4). Therefore, other aetiological factors, including genetic, radiation exposure and environmental pollution, must be involved in the development of lung cancer. 
Environmental risks. Environmental factors have been implicated in the vast majority of human cancers, particularly lung cancer (4). Environmental factors associated with lung cancer include smoking, passive smoking, air pollution, exposure to carcinogenic chemicals and alcohol consumption. In addition, exposure to radon, heavy metals used in smelting and asbestos markedly increases the risk of developing lung cancer (6).

Smoking as a causative agent. Cigarette smoking is thought to cause $85 \%$ of lung cancer cases; however, only a fraction of long-term smokers develop lung cancer. The development of lung cancer depends on how much and how long an individual has smoked, as well as other causes of lung cancer. Men and women who smoke are 23 and $13 \%$, respectively, more likely to develop lung cancer compared with never-smokers (5).

In addition, passive smoking or inhalation of second-hand smoke is associated with respiratory illness and lung cancer in non-smokers. Children who had early exposure to passive smoking may be at a high risk of developing lung cancer later in life. A previous study reported that 9 million American children aged $<5$ years are affected by passive smoking (7).

Tobacco smoke contains polycyclic aromatic hydrocarbons (PAHs), which are common DNA-damaging carcinogens. PAHs interact with DNA and form mutagenic DNA adducts, which trigger the onset of lung cancer. Notably, smokers have higher levels of PAH-DNA adduct formation than non-smokers (8).

Indoor air pollution. Indoor environments are widely polluted with a complex mixture of gases and particles produced via combustion. Exposure to solid fuel smoke has been associated with various diseases, including chronic obstructive pulmonary disease, acute respiratory infection and various types of cancer, particularly lung cancer (9).

Incomplete combustion results in the emission of gases, including sulphur dioxide, carbon monoxide, carbon dioxide, and nitrogen oxide, as well as PAHs, formaldehyde and heavy metals. Approximately, half of the world's population is at risk of developing respiratory diseases due to the use of unprocessed biomass fuel and coal for cooking and heating $(10,11)$. A previous study conducted in China demonstrated that indoor air pollution has an important role in the development of lung cancer among Chinese women, particularly among never-smokers (9). The study reported that women who cook twice a day have a 2-fold risk of developing lung cancer (9). Another study reported that the mortality rate associated with lung cancer in Xuanwei, China was higher among users of smoky coal than among users of smokeless coal; this indicated that indoor air pollution caused by smoky coal is a major cause of lung cancer in this region (12). These studies suggested an aetiological link between indoor air pollution and lung cancer.

Outdoor air pollution. Outdoor air pollution, which is mainly caused by emissions from transportation, power generation, factories, industrial plants and agriculture, increases the risk of respiratory and cardiovascular diseases (10). The International Agency for Research on Cancer classified outdoor air pollution as Group 1 carcinogens to humans (13). PAHs constitute one of the major classes of carcinogens present in urban air pollution, and arise from incomplete combustion of wood or fuel and from industrial or vehicle exhaust emissions. Long-term exposure to PAHs has been shown to increase the incidence of lung cancer (8).

Vehicle engine exhaust emissions are a complex mixture of numerous carcinogenic and mutagenic chemicals that are involved in lung tumourigenesis. Raaschou-Nielsen et al (10) demonstrated that non-smokers and residents near heavy traffic roads are at a high risk of air pollution-associated lung cancer. Furthermore, they reported that nitrogen oxide and nitrogen dioxide emitted from vehicle engine exhaust are causative agents of lung cancer in urban populations (10). Animal studies have also confirmed that exposure to diesel emission promotes lung tumourigenesis $(9,14)$.

Sulphur dioxide, a major air pollutant and co-carcinogen, increases respiratory disease-associated mortality (14). A high mortality rate has been observed among workers employed in the paper and pulp industry, and among those exposed to sulphur dioxide combined with arsenic. Other studies suggested that sulphur dioxide exposure in the paper and pulp industry contributes to lung carcinogenesis $(15,16)$.

Pope et al (17) reported that long-term exposure to air pollutants significantly increased the lung cancer-associated mortality rate among people living in or near metropolitan areas. In their study, the association between air pollution and lung cancer remained significantly high, even after controlling for factors such as cigarette smoking, body mass index, diet and occupational exposure (17). This result suggested that air pollution contributes to the development of lung cancer.

Heritable factors. Environmental factors and somatic events are the major factors contributing to the development of sporadic lung cancer. Genetic factors are also a significant contributor, but only a few specific genes and other genetic factors affecting lung cancer have been identified to date $(6,18)$.

Twin studies are a valuable source of information to unravel the epidemiology of cancer. Comparison of the concordance of cancer between monozygotic (genetically identical) and dizygotic (sharing half of the segregating genes) twins may reveal the influence of hereditary or environmental factors on the familial pattern of cancer (19). A twin study revealed that shared environments and lifestyles, but not genetic factors, affect the onset of lung cancer, and that smoking habits are likely the reason for the familial pattern of lung cancer in twins (20). Another study suggested that genetic factors do not exhibit strong prognostic value for lung cancer risk in twins (18). In addition, a low probability of lung cancer development was observed in a person whose identical twin was suffering from lung cancer (21). Conversely, a previous study (6) assessed the risk of lung cancer in 45,000 twins (monozygotic and dizygotic) and demonstrated that monozygotic and dizygotic twins had a 7.7- and 6.7-fold increased risk, respectively (6). These results reflected the combined effect of genetic and environmental factors.

Previous studies have demonstrated that factors such as having an affected first-degree relative, early-onset lung cancer and multiple affected family members significantly increase the risk of lung cancer $(22,23)$. The relatively strong influence of genetic factors among first-degree relatives suggests 
that major gaps exist in our knowledge of the genetics of lung cancer.

\section{Molecular biology of lung cancer}

Chromosomal abnormalities. Cytogenetic analyses of lung cancer revealed recurrent chromosomal alterations. Numerous chromosomal abnormalities have been documented in lung cancer; these abnormalities include allelic loss, isochromosomes, unbalanced translocation and loss of heterozygosity (LOH) (24).

Extensive aneusomy (gain of 2 or more chromosomes per cell) is the most commonly observed chromosomal change in patients with NSCLC $(25,26)$. Using classical cytogenetic techniques, interphase fluorescence in situ hybridisation (FISH) and comparative genomic hybridisation (CGH), 50\% of NSCLC samples showed gains of chromosomes 6, 7 and 8 (27,28). Gains involving chromosome 5p are another frequent abnormality observed in NSCLC. Karyotype studies identified polysomy in most parts of chromosome 7 (29-31). Furthermore, large areas of deletions in chromosomes 3 and $9 p$ or amplifications in chromosomes 1 and $3 q$ are recurrently observed in lung cancer (30). As determined by $\mathrm{LOH}$ and $\mathrm{CGH}$, higher rates of chromosomal alterations have been observed in squamous cell carcinoma than in adenocarcinoma. In addition, $\mathrm{LOH}$ at chromosome 3 p14 was more prevalent in current smokers than in former smokers (32-34).

Oncogenes and tumour suppressor genes. Alterations in oncogenes and tumour suppressor genes have been shown to trigger cancer (35). Therefore, investigating these genes is important to analyse the molecular mechanisms underlying cancer. Several oncogenes and tumour suppressor genes have been associated with lung cancer.

RAS genes were one of the first documented oncogenes and were named H-RAS (homologous to heavy murine sarcoma virus oncogene), K-RAS (homologous to Kirsten murine sarcoma virus oncogene) and N-RAS (initially isolated from neuroblastoma cell lines) (36). K-RAS encodes a G-protein that controls signalling pathways regulating cell proliferation, differentiation and survival. Activating mutations in the K-RAS oncogene are the most common oncogenic alterations in lung adenocarcinoma, occurring in $25-40 \%$ of cases. K-RAS mutations are more frequently observed in Western populations than in Asian populations, and in male smokers than in female smokers $(37,38)$.

Epidermal growth factor receptor (EGFR), which is a 1,186-amino acid tyrosine kinase receptor protein located on the cell surface, is mainly involved in cell growth and division (39). The EGFR belongs to the avian erythroblastosis oncogene B (ERBB) family, which includes ERBB1 (also known as EGFR), ERBB2 [also known as human epidermal growth factor receptor 2 (HER2)], ERBB3 and ERBB4 (40). EGFR overexpression in lung cancer was initially reported in 1993, where it was observed in 43-89\% of NSCLC cases (41). Of the known EGFR tyrosine kinase domain mutations, $>90 \%$ occur as point mutations or deletions in exon $19(42,43)$. Acquired EGFR mutations are frequently identified among female non-smokers in East Asia, and indicate that they will be responsive to EGFR-targeted therapies (44).
B-RAF is a serine threonine kinase and one of the three members of the RAF family, which includes A-RAF, B-RAF and RAF-1. Oncogenic mutations in B-RAF occur in 6-8\% of NSCLC cases, accounting for $>90,000$ deaths per year worldwide (45). The vast majority of B-RAF mutations in lung cancer correspond to the hotspot transversion mutation T1799A at exon 15. The B-RAF-V600E variant, which is the most frequent mutant allele, has been used to match patients genetically to B-RAF inhibitor therapy (46). B-RAF mutations are prevalent in females with lung adenocarcinoma, regardless of smoking history (47).

HER2, similar to EGFR, is a member of the ERBB family of receptor tyrosine kinases. HER 2 mutations have been identified in $2-4 \%$ of NSCLC cases, and the majority of mutations involved insertions at exon 20 (48). HER2 mutations are prevalent in Asian female patients who have never smoked; these mutations are also more common in adenocarcinoma than in other types of lung cancer (49). A novel germline point mutation HER2 G660D has been recently identified in never-smoker relatives with multi-generational lung adenocarcinoma (50).

The echinoderm microtubule associated protein-like 4 (EML4) and anaplastic lymphoma kinase (ALK) fusion protein is among the latest molecular targets for NSCLC therapy. Rearrangement of the EML4 and ALK genes was observed in $3-7 \%$ of patients with NSCLC (51). ALK-positive lung cancer patients are typically young, regardless of ethnicity, with minimal or no exposure to tobacco, and have adenocarcinoma (52). Multiple transcript variants of the EML4-ALK fusion gene have been observed in NSCLC. Among these variants, E13:A20 (including exon 13 of EML4 and exon 20 of ALK) and E6a/b:A20 (variant 3a/b) are the most common, accounting for 33 and 29\%, respectively, of all the EML4-ALK variants recognised in NSCLC (53).

ROS1 is a proto-oncogene located on chromosome $6 \mathrm{p} 22$ and is involved in chromosomal translocations associated with lung cancer. ROS1 fusions are widespread in never-smokers with a histological diagnosis of adenocarcinoma (54). In patients with NSCLC, chromosomal translocations have been identified by ROS1-solute carrier family 34 member 2 (SLC34A2) and ROS1-cluster of differentiation 74 (CD74) fusions, which involve the fusion of the 5' region of SLC34A2 with the $3^{\prime}$ region of ROS1 and the fusion of the 5' region of CD74 with the 3' region of ROS1, respectively (55). In addition to SLC34A2 and CD74 fusions, four new ROS1 fusion partners, including tropomyosin 3 , syndecan 4 , ezrin and leucine-rich repeats and immunoglobulin-like domains 3 , have been identified in NSCLC $(55,56)$.

Rearranged during transfection (RET) is a novel oncogenic driver which is located on chromosome 10q11.2 and has been detected in $\sim 1.3 \%$ of lung cancer cases (57). RET, a receptor tyrosine kinase, is involved in cell proliferation, neuronal navigation, cell differentiation and cell migration. Patients carrying a RET fusion are typically young, never-smokers with early lymph node metastasis and poor differentiation. RET fusions occurs in patients without other common oncogenes, such as EGFR, K-RAS and ALK $(58,59)$. Four RET fusion partners, including kinesin family member $5 \mathrm{~B}$, tripartite motif-containing 33 , coiled-coil domain-containing 6 and nuclear receptor coactivator 4 , have been reported in NSCLC (60). 
Tumour protein p53 (TP53) is a tumour suppressor gene located on chromosome $17 \mathrm{p} 13$, which encodes a protein that regulates cell division, growth and apoptosis, and inhibits cancer development. Mutations in the TP53 gene have been shown to occur in $50 \%$ of NSCLC cases (61), and they were more dominant in squamous cell carcinoma than in adenocarcinoma among NSCLC cases (62). Patients with tobacco-associated cancer have a higher risk for TP53 mutations than patients who have never smoked $(62,63)$. TP53 mutations have been associated with exposure to environmental tobacco smoke and a smoking history (61).

MicroRNA in lung cancer. MicroRNAs (miRNAs) are a class of small non-coding RNA gene products 20-22-nucleotides in length. The function of miRNAs is to regulate gene expression; however, they have a substantial role in the pathogenesis of human cancer and are recurrently abnormally expressed in cancers (64).

Johnson et al (65) were the first to identify a role for miRNA expression in the regulation of genes associated with lung cancer. They demonstrated that human RAS genes are regulated by let-7, a family of miRNAs that participate in the timing of cell fate determination. They also detected lower expression levels of let-7 in lung cancer than in normal tissues and higher expression levels of RAS proteins in tumour tissues than in adjacent normal tissues (65). Members of the let-7 family can inhibit the expression of several oncogenes, including RAS, MYC and high mobility group AT-hook 2 (66). Recent investigations have demonstrated that miRNA regulates EGFR in lung cancer. An inhibitor of miR-128b upregulated EGFR expression in an EGFR-expressing NSCLC cell line, and treatment with miR-128b mimics significantly reduced EGFR expression (67). In addition, p53 expression has been associated with the expression of miR-34a, miR-34b and miR-34c in lung cancer, suggesting that miR-34 regulates apoptosis as a target of p53 (68).

A single miRNA can influence the expression of several mRNAs. Determining the biological pathways of miRNAs helps to elucidate the carcinogenic mechanisms and improve current diagnostic and therapeutic methods.

\section{Familial lung cancer}

Significance of familial cancer. Familial cancer is characterised by gene mutations in two or more first-degree relatives diagnosed with the same type of cancer; this condition is influenced by a hereditary predisposition, variable gene penetrance and environmental factors (1). Familial cancer is attributable to shared genetic and environmental factors. Hereditary predisposition, which is passed through successive generations of a family, has been implicated in 10-15\% of cancer cases. Breast, colon, bladder and ovarian cancers are commonly associated with an hereditary predisposition $(69,70)$.

The majority of patients with cancer have no family history of cancer, and genetic alterations are somatic (only in the cancer cells) rather than germline (heritable variation in the lineage of germ cells). Approximately $1-5 \%$ of human cancers develop because of known germline defects $(69,71)$. In general, all major hereditary cancer types differ from their sporadic counterparts with respect to the underlying physiological and pathological mechanisms (1,71). Genome-wide association and susceptibility studies are useful for the evaluation of inherited genetic risks in populations with unique characteristics or environmental exposure.

Currently, research on hereditary cancer is regarded as being of primary importance with an immediate health impact. The discovery of tumour-predisposing mutations and the development of appropriate genetic tests are crucial for the identification of healthy individuals who are at risk of certain cancer types, and thus may benefit from timely medical intervention (71). Identifying driver mutations and screening high-risk populations for germline mutations can reduce the mortality rate among cancer patients. For example, intensive surveillance programmes ensure an early diagnosis, and preventive surgery may reduce cancer-associated mortality $(1,72)$.

A comprehensive review identified 54 hereditary cancer syndromes. The majority of these cancer-susceptibility syndromes are autosomal dominant, including retinoblastoma (Rb), Li-Fraumeni syndrome, neurofibromatosis, von Hippel-Lindau (VHL) disease, familial adenomatous polyposis and hereditary breast and ovarian cancer (73). Certain genetic mutations have been associated with specific types of hereditary cancer; associations have been reported for $\mathrm{Rb}$ and the $\mathrm{Rb}$ tumour suppressor gene, Li-Fraumeni syndrome and the P53 tumour suppressor gene, VHL disease and the VHL tumour suppressor gene, and familial adenomatous polyposis and the adenomatous polyposis coli tumour suppressor gene. Hereditary cancer syndromes have also been associated with oncogenic mutations. Hereditary forms of medullary thyroid cancer develop because of inherited mutations in the RET oncogene; thus, these forms of cancer are sensitive to the RET tyrosine kinase inhibitor Vandetanib (74).

Some hereditary cancers have been associated with mutations in multiple genes. A list of genes causing hereditary breast cancer is rapidly expanding, of which breast cancer 1 (BRCA1) and BRCA 2 are the most studied. BRCA1 and 2 genes have a central role in the DNA repair system via homologous recombination, and their absence increases cell sensitivity to particular DNA damaging agents $(75,76)$. Approximately $15 \%$ of ovarian cancers are also caused by the inherited BRCA1 and BRCA2 mutations. BRCA1- and BRCA2-related cancers show various genetic abnormalities, although both exhibit increased numbers of gross chromosomal aberrations and a high tumour grade (77). Familial colorectal cancer (CRC) usually develops early, and almost all tumours result from hereditary non-polyposis CRC (78). CRC is triggered by defects in the DNA repair system, usually germline mutations in the Mut L homolog 1, Mut S homolog 2, postmeiotic segregation increased 2 and Mut S homolog 6 genes $(78,79)$. In addition, high-level microsatellite instability has been observed in CRC patients (80).

Hereditary tumours are increasingly recognised as exhibiting distinct bio-clinical characteristics, and thus require tailored treatment strategies. With the increasing risk of familial cancers, identification of culprit genes in families is imperative. Such investigations will permit the identification of individuals and families who are at a high risk of a particular cancer, as well as the active implementation of preventive measures. Researchers are interested in using 
familial cancer models to identify individual and groups of genes responsible for cancer development, to identify novel cancer-associated genes and biomarkers, and to estimate the risk of cancer in members of the general population. Studies on familial cancers have revealed various important oncogenes and tumour suppressor genes, including BRCA1, BRCA2, Rb and VHL (77,78). These findings provide opportunities for the prevention of cancer and the early detection of cancer through evidence-based screening.

Familial risk of lung cancer. Lung cancer is predominantly associated with environmental factors, including smoking and air pollution; however, familial causes of lung cancer cannot be ignored. Familial aggregation of lung cancer is frequently observed in clinical studies (81-84). Familial lung cancer is more complex than other familial cancers, and can be caused by shared environmental factors or shared genetic factors among family members (85). The role of genetic factors in tumour development in lung cancer is poorly understood, as genetic factors are masked by the influence of environmental factors, including smoking, air pollution and coal burning (86). The development of lung cancer in never-smokers is a complex clinical problem, and a large number of studies have indicated that individuals with a family history of lung cancer are twoto three-fold more susceptible to lung cancer development than those without such a history; this association is strongest for those whose siblings have been affected by lung cancer (22). The risk of lung cancer in individuals with a family history of cancer among first-degree relatives is increased by $\sim 50 \%$ compared with those without a family history, and this association is not affected by gender, ethnicity, histological types and other known lung cancer risk factors (23).

Studies on familial cases of lung cancer have provided evidence for hereditary transmission of lung cancer from one generation to the next generation. Approximately $8 \%$ of lung cancers are inherited or occur as a result of a genetic predisposition $(82,87)$. In a previous study, first-degree relatives of a lung cancer proband had a greater than normal likelihood of developing cancer compared with other non-smokers because of genetic recombination (83).

Lung cancer rates in Xuanwei (Yunnan, China) are 4-5 times higher than the average in China, and air pollution is the main reason for lung cancer in Xuanwei. Often, multiple members of families in this region are diagnosed with lung cancer (4). Aside from the environmental factors, genetic factors have also been associated with the risk of lung cancer, particularly among women in Xuanwei (88). A study in China determined the risk of lung cancer among the relatives of a patient with lung cancer and found that female relatives, particularly the mothers, had a higher risk of developing lung cancer than male relatives. However, the exact genetic mechanisms influencing lung cancer susceptibility in female relatives in China are unknown (89). Indoor cooking is still practiced in some rural areas of China and in numerous other countries; this practice can be considered an important risk factor for lung cancer among women (11). The abovementioned studies suggest that lung cancer is likely to develop in genetically predisposed individuals.

Population-based studies on familial lung cancer. Population-based studies on familial cancer are vital for the elucidation of the genetic mechanisms of cancer, as well as for risk identification and occurrence ratios of mutation-associated cancer in a certain population. Another approach for the investigation of familial lung cancer is to classify the relatives of a proband according to their degree of risk for cancer.

The Nationwide Swedish Family-Cancer Database is the largest dataset on familial cancer (90). According to the database, for the dominance effect in offspring, information from parental probands is authentic, whereas risk analysis between siblings without affected parents provides clues about possible recessive effects (90). The database is used to search for evidence of a genetic predisposition to lung cancer; several studies found that a familial risk for lung cancer among offspring was increased to $1.77 \%$ when the parents were affected, and that the risk was higher among siblings $(2.15 \%)$ than between offspring and parents (72). An Icelandic population was investigated to assess the contribution of genetic factors to the risk of lung cancer development; the investigation involved 2,756 patients and revealed the importance of genetic susceptibility in the progression of lung cancer (87). Notably, their results demonstrated that a familial predisposition positively influenced lung cancer development due to the significantly increased risk ratio (RR) for the first-, second- and third-degree relatives of lung cancer patients (87). However, shared environmental factors could not be ignored, as a considerably increased RR was also observed in the spouses of lung cancer patients (87).

Another study investigated the association between lung cancer and genetic factors in 102,255 patients; it was demonstrated that the risk of lung cancer development was significantly elevated among the first-degree relatives of a lung cancer patient (91). When a family history of tobacco exposure was accounted for, the results suggested that females were more likely to develop lung cancer than males (91). A previous study estimated the risk of lung cancer among the white and black relatives of a proband, and demonstrated that the first-degree relatives of a black individual with early-onset lung cancer had a greater risk for lung cancer than their white relatives, and the risk was significantly increased by a history of tobacco smoking (92). In addition, an elevated risk was observed among individuals whose father or siblings were affected by lung cancer; both males and females were similarly affected. These findings support the aggregation of lung cancer in families (84). A previous study investigated the importance of smoking and a family history of various respiratory diseases in women with lung cancer; there was a significant association between lung cancer and both smoking and a family history of respiratory disease (93). In addition, women with a history of bronchitis, pneumonia and emphysema were shown to have a higher risk of developing lung cancer than those with a family history of asthma or hay fever (93).

Population-based studies on familial lung cancer have indicated that genetic factors increase the risk for lung cancer, although environmental factors remain the most important causes. Furthermore, the genetic susceptibility for lung cancer is higher in females than in males.

Genetics of familial lung cancer. Identifying novel genes associated with familial lung cancer is challenging. To date, only a few lung cancer-specific genes have been identified. 
Therefore, further improvements in the understanding of cancer genetics are necessary. Whole-genome sequencing and exome sequencing can be used to identify genes that cause diseases, not only in probands but also in the successive generations (94).

Several studies have reported that familial lung cancer is associated with an increased risk of NSCLC for both smokers and non-smokers $(44,81,83)$. A previous study demonstrated that almost a fifth (18\%) of 230 NSCLC patients who had never smoked had a family history of lung cancer, and suggested a potential link between EGFR mutations and familial lung cancer (81).

Genome-wide association studies independently revealed that the chromosomal region 15q24-25.1 is associated with an increased risk for nicotine dependence and lung cancer development $(95,96)$. This region contains the nicotinic acetylcholine receptor subunit gene and a single nucleotide polymorphism. The risk for lung cancer was relatively higher in this region for familial cases; more so than sporadic cases (96). In another study, the risk of lung cancer was more than five-fold higher among individuals who had a family history of lung cancer and two copies of the high-risk alleles rs8034191 and rs1051730 (82). The clinical significance of these findings remains unclear. A regulator of $\mathrm{G}$ protein signalling family (RGS) member, RGS17, has been identified as a causative gene in the chromosome $6 p$ locus, where some common variants have been associated with familial cancer, although the association of the RGS17 gene with lung cancer has not been reported previously. A functional study indicated that RGS17 is highly expressed in tumour tissues and that its overexpression increases the proliferation rate of tumour cells (97).

Researchers from Japan recently analysed 9 members of a large family (20 members) suffering from an autosomal dominant lung adenocarcinoma. The whole-exome sequencing of two affected and two normal individuals of the same family revealed a novel germline mutation (G660D) in the transmembrane domain of the HER 2 gene located in chromosome 17 and exon 17. In addition, they sequenced exon 17 of the HER2 gene of sporadic lung cancers. The HER2 G660D germline mutation was not detected through sequencing, although another novel mutation, $\mathrm{V} 659 \mathrm{E}$, in a patient with adenocarcinoma was identified. The study concluded that the novel HER2 mutation is potentially oncogenic, causing hereditary and sporadic lung adenocarcinoma (50).

In a European family, multiple members suffering from NSCLC were associated with the germline transmission of an EGFR variant, namely EGFR T790M. In the study, the EGFR T790M variant resulted in a subtle alteration in EGFR signalling and enhanced the effect of other activating mutations in the same region (98). Another study reported that 5/10 NSCLCcases carried the EGFR T790M variant. Of these five cases, only two had a family history of lung cancer. This mutation has been associated with familial lung adenocarcinoma (99).

Mapping of the lung cancer genome is an important step towards understanding the pathogenesis of lung cancer. Whole-genome analyses of cancer have identified numerous novel candidate genes. However, large-scale collaborative efforts are required to identify novel variants and to improve the understanding of already known variants. Whole-genome sequencing of familial lung cancer provides an opportunity for this purpose.

\section{Conclusion}

Lung cancer is the most common fatal cancer worldwide. Environmental factors, including smoking, passive smoking, and indoor and outdoor air pollution, are the major causes of lung cancer, although genetic factors likely also contribute to lung cancer development. Numerous studies have provided evidence that the genetic makeup of an individual is associated with lung cancer susceptibility. The familial aggregation (or occurrence) of lung cancer may be caused by shared environmental exposures, an inherited susceptibility or a combination of both. Familial lung cancer represents a good model for investigating the association between environmental and genetic factors, as well as for identifying the susceptibility genes of lung cancer. Studies on familial lung cancer may help to elucidate the aetiology and mechanisms of lung cancer and to identify novel biomarkers for early detection and diagnosis, targeted therapy and improved preventive measures. These endeavours are a part of the core concepts of 'precision medicine'. However, although some studies based on familial lung cancer have been performed, only a few genes have been identified among patients with a family history of lung cancer. Research on familial lung cancer will be an enormous endeavour. Collectively, molecular and whole-genome studies on familial lung cancer should be conducted to identify the genes responsible for lung cancer.

\section{Acknowledgements}

This study was supported by the 973 Program (grant no. 2011CB510104) and the Natural Science Foundation of China (grant no. 81272617). Furthermore, the study was sponsored by the CAS-TWAS President's Fellowship for International PhD Students (MK).

\section{References}

1. Brentnall T: Management strategies for patients with hereditary pancreatic cancer. Curr Treat Options Oncol 6: 437-445, 2005.

2. Riaz SP, Linklater KM, Page R, Peake MD, Møller H and Lüchtenborg M: Recent trends in resection rates among non-small cell lung cancer patients in England. Thorax 67: 811-814, 2012.

3. Chambers A, Routledge T, Pilling J and Scarci M: In elderly patients with lung cancer is resection justified in terms of morbidity, mortality and residual quality of life? Interact Cardiovasc Thorac Surg 10: 1015-1021, 2010.

4. Cao Y and Gao HP: Prevalence and causes of air pollution and lung cancer in Xuanwei city and Fuyuan County, Yunnan province, China. Front Med 6: 217-220, 2012.

5. World Health Organization: Cancer. Fact Sheet No 297. http://www.who.int/mediacentre/factsheets/fs297/en/. Accessed March 20, 2015.

6. Lichtenstein P, Holm NV, Verksalo PK, Iliadou A, Kaprio J, Koskenvuo M, Pukkala E, Skytthe A and Hemminki K: Environmental and heritable factors in the causation of cancer-analyses of cohort of twins from Sweden, Denmark, and Finland. N Engl J Med 343: 78-85, 2000.

7. American Cancer Society: Cancer Facts \& Figures 1993 http://www.cancer.org/research/cancerfactsstatistics/allcancerfactsfigures/. Accessed March 20, 2015.

8. Geneste O, Camus AM, Castegnaro M, Petruzzelli S, Macchiarini P, Angeletti CA, Giuntini C and Bartsch H: Comparison of pulmonary DNA adduct levels, measured by 32P-postlabelling and aryl hydrocarbon hydroxylase activity in lung parenchyma of smokers and ex-smokers. Carcinogenesis 12: 1301-1305, 1991.

9. Smith KR, Samet JM, Romieu I and Bruce N: Indoor air pollution in developing countries and acute lower respiratory infection in children. Thorax 55: 518-532, 2000. 
10. Raaschou-Nielsen OR, Andersen ZJ, Hvidberg M, Jensen SS, Ketzel M, Sørensen M, Loft S, Overvad K and Tjønneland A: Lung cancer incidence and long-term exposure to air pollution from traffic. Environ Health Perspect 119: 860-865, 2011.

11. Mu L, Liu L, Niu R, Zhao B, Shi J, Li Y, Swanson M, Scheider W, $\mathrm{Su}$ J, Chang SC, et al: Indoor air pollution and risk of lung cancer among chinese female non-smokers. Cancer Causes Control 24: 439-450, 2013

12. Barone-Adesi F, Chapman RS, Silverman DT, He X, Hu W, Vermeulen R, Ning B, Fraumeni JF Jr, Rothman N and Lan Q: Risk of lung cancer associated with domestic use of coal in Xuanwei, China: Retrospective cohort study. BMJ 345: e5414, 2012.

13. International Agency for Research on Cancer: IARC monographs on the evaluation of carinogenic risks to humans 2011. http://monographs.iarc.fr/ENG/Classification/. Accessed March 20, 2015

14. Ohyama K, Ito $\mathrm{T}$ and Kanisawa $\mathrm{M}$ : The roles of diesel exhaust-particle extracts and the promotive effects of $\mathrm{NO}_{2}$ and/or $\mathrm{SO}_{2}$ exposure on rat lung tumorigenesis. Cancer 139: 189-197, 1999.

15. Lee WJ, Teschke K, Kauppinen T, Andersen A, Jäppinen P, Szadkowska-Stanczyk I, Pearce N, Persson B, Bergeret A, Facchini LA, et al: Mortality from lung cancer in workers exposed to sulfur dioxide in the pulp and paper industry. Environ Health Perspect 110: 991-995, 2002.

16. Langseth $\mathrm{H}$ and Andersen A: Cancer incidence among male pulp and paper workers in Norway. Scand J Work Environ Health 26 : 99-105, 2000.

17. Pope CA III, Burnett RT, Thun MJ, Calle EE, Krewski D, Ito K and Thurston GD: Lung cancer, cardiopulmonary mortality, and long-term exposure to fine particulate air pollution. JAMA 287 : $1132-1141,2002$

18. Braun MM, Caporaso NE, Page WF and Hoover RN: Genetic component of lung cancer: Cohort study of twins. Lancet 344 : 440-443, 1994

19. Neale MC and Cardon LR (eds): Methodology for genetic studies of twin and families. 1st edition. Kluwer Academic Publishers, Dordrecht, pp237-238, 1992.

20. Ahlbom A, Lichtenstein P, Malmström H, Feychting M Hemminki K and Pedersen NL: Cancer in twins: Genetic and non-genetic familial risk factor. J Nat Canc Isnt 89: 287-293, 1997.

21. Carmelli D, Swan GE, Robinette D and Fabsitz R: Genetic influence on smoking - a study of male twins. N Engl J Med 327: 829-833, 1992

22. Coté ML, Liu M, Bonassi S, Neri M, Schwartz AG, Christiani DC, Spitz MR, Muscat JE, Rennert G, Aben KK, et al: Increased risk of lung cancer in individuals with a family history of the disease: A pooled analysis from the International lung cancer consortium. Eur J Cancer 48: 1957-1968, 2012.

23. Bailey-Wilson JE, Amos CI, Pinney SM, Petersen GM, de Andrade M, Wiest JS, Fain P, Schwartz AG, You M, Franklin W, et al: A major lung cancer susceptibility locus maps to chromosome 6q23-25. Am J Hum Genet 75: 460-474, 2004.

24. Mitsuuchi Y and Testa JR: Cytogenetics and molecular genetics of lung cancer. Am J Med Genet 115: 183-188, 2002.

25. Zochbauer-Muller ZS, Gazdar AF and Minna JD: Molecular pathogenesis of lung cancer. Annu Rev Physiol 64: 681-708, 2002.

26. Schenk T, Ackermann J, Brunner C, Schenk P, Zojer N, Roka S and Drach J: Detection of chromosomal aneuploidy by interphase fluorescence in situ hybridization in bronchoscopically gained cells from lung cancer patients. Chest 111: 1691-1696, 1997

27. Kang JU, Koo SH, Kwon KC, Park JW, Shin SY, Kim JM and Jung SS: High frequency of genetic alterations in non-small cell lung cancer detected by multi-target fluorescence in situ hybridization. J Korean Med Sci 22 (Suppl): S47-S51, 2007.

28. Kettunen E, Salmenkivi K, Vuopala K, Toljamo T, Kuosma E, Norppa H, Knuutila S, Kaleva S, Huuskonen MS and Anttila S: Copy number gains on 5p15, 6p11-q11,7p12, and 8q24 are rare in sputum cells of individuals at high risk of lung cancer. Lung Cancer 54: 169-176, 2006.

29. Luk C, Tsao MS, Bayani J, Shepherd F and Squire JA: Molecular cytogenetic analysis of non-small cell lung carcinoma by spectral karyotyping and comparative genomic hybridization. Cancer Genet Cytogenet 125: 87-99, 2001

30. Lu YJ, Dong XY, Shipley J, Zhang RG and Cheng SJ: Chromosome 3 imbalances are the most frequent aberration found in non-small cell lung carcinoma. Lung Cancer 23: 61-66, 1999.

31. Testa JR, Siegfried JM, Liu Z, Hunt JD, Feder MM, Litwin S, Zhou JY, Taguchi T and Keller SM: Cytogenetic analysis of 63 non-small cell lung carcinomas: Recurrent chromosome alterations amid frequent and widespread genomic upheaval. Gene Chrom Cancer 11: 178-194, 1994.
32. Toyooka S, Suzuki M, Tsuda T, Toyooka KO, Maruyama R, Tsukuda K, Fukuyama Y, Iizasa T, Fujisawa T, Shimizu N, et al: Dose effect of smoking on aberrant methylation in non-small cell lung cancer. Int J Cancer 110: 462-464, 2004

33. Wistuba II, Berry J, Behrens C, Maitra A, Shivapurkar N, Milchgrub S, Mackay B, Minna JD and Gazdar AF: Molecular changes in the bronchial epithelium of patients with small cell lung cancer. Clin Cancer Res 6: 2604-2610, 2000.

34. Sato S, Nakamura Y and Tsuchiya E: Difference of allelotype between squamous cell carcinoma and adenocarcinoma of the lung. Cancer Res 54: 5652-5655, 1994.

35. Osada $\mathrm{H}$ and Takahashi T: Genetic alterations of multiple tumor suppressors and oncogenes in the carcinogenesis and progression of lung cancer. Oncogene 21: 7421-7434, 2002.

36. Downward J: The RAS superfamily of small GTP binding proteins. Trends Biochem Sci 15: 469-472, 1990

37. Riely GJ, Kris MG, Rosenbaum D, Marks J, Li A, Chitale DA, Nafa K, Riedel ER, Hsu M, Pao W, et al: Frequency and distinctive spectrum of KRAS mutations in never smokers with lung adenocarcinoma. Clin Cancer Res 14: 5731-5734, 2008.

38. Rodenhuis S and Slebos RJ: Clinical significance of Ras oncogene activation in human lung cancer. Cancer Res 52 (Suppl 9): S2665-S2669, 1992.

39. Bethune G, Bethune D, Ridgway N and Xu Z: Epidermal growth factor receptor (EGFR) in lung cancer: An overview and update. J Thorac Dis 2: 48-51, 2010.

40. Inamura K, Ninomiya H, Ishikawa $Y$ and Matsubara O: Is the epidermal growth factor receptor status in lung cancers reflected in clinicopathologic features? Arch Pathol Lab Med 134: 66-72, 2010.

41. Zhou CC, Zhou SW, Pan H, Su B and Gao ZQ: Detection of epidermal growth factor receptor mutations in non-small cell lung cancer by real-time PCR using TaqMan-MGB probes. Zhonghua Zhong Liu Za Zhi 29: 119-123, 2007 (In Chinese).

42. Gupta R, Dastane AM, Forozan F, Riley-Portuguez A, Chung F, Lopategui J and Marchevsky AM: Evaluation of EGFR abnormalities in patients with pulmonary adenocarcinoma: The need to test neoplasms with more than one method. Mod Pathol 22: 128-133, 2009.

43. Ladanyi $\mathrm{M}$ and Pao W: Lung adenocarcinoma: Guiding EGFR-targeted therapy and beyond. Mod Pathol 21 (Suppl 2): S16-S22, 2008

44. Sun S, Schiller JH and Gazdar AF: Lung cancer in never smokers-a different disease. Nat Rev Cancer 7: 778-790, 2007.

45. Lin L, Asthana S, Chan E, Bandyopadhyay S, Martins MM, Olivas V, Yan JJ, Pham L, Wang MM, Bollag G, et al: Mapping the molecular determinants of BRAF oncogene dependence in human lung cancer. Proc Natl Acad Sci USA 111: E748-E757, 2014.

46. Tissot C, Couraud S, Tanguy R, Bringuier PP, Girard N and Souquet PJ: Clinical characteristics and outcome of patients with lung cancer harboring BRAF mutations. Lung Cancer 91: 23-28, 2016.

47. Garnett MJ and Marais R: Guilty as charged: B-RAF is a human oncogene. Cancer Cell 6: 313-319, 2004.

48. Mar N, Vredenburgh JJ and Wasser JS: Targeting HER2 in the treatment of non-small cell lung cancer. Lung Cancer 87: $220-225,2015$

49. Shimamura T, Ji H, Minami Y, Thomas RK, Lowell AM, Shah K, Greulich H, Glatt KA, Meyerson M, Shapiro GI and Wong KK: Non-small cell lung cancer and $\mathrm{Ba} / \mathrm{F} 3$ transformed cell harboring the ERBB2 G776ins V G/C mutations are sensitive to the dual specific epidermal growth factor receptor and ERBB inhibitor HKI-272. Cancer Res 66: 6487-6491, 2006.

50. Yamamoto H,Higasa K, Sakaguchi M, Shien K, Soh J, Ichimura K, Furukawa M, Hashida S, Tsukuda K, Takigawa N, et al: Novel germline mutation in the transmembrane domain of HER 2 in familial lung adenocarcinomas. J Natl Can Inst 106: djt338, 2014.

51. Soda M, Choi YL,Enomoto M, Takada S, Yamashita Y, Ishikawa S, Fujiwara S, Watanabe H, Kurashina K, Hatanaka H, et al: Identification of transforming EML4-ALK fusion gene non-small cell lung cancer. Nature 448: 561-566, 2007.

52. Kwak EL, Bang YJ, Camidge DR, Shaw AT, Solomon B, Maki RG, Ou SH, Dezube BJ, Jänne PA, Costa DB, et al: Anaplastic lymphoma kinase inhibition in non-small cell lung cancer. N Engl J Med 363: 1693-1703, 2010.

53. Sasaki T, Rodig SJ, Chirieac LR and Jänne PA: The biology and treatment of EML4-ALK non-small cell lung cancer. Eur J Can 46: 1773-1780, 2010.

54. Cai W, Li X, Su C, Fan L, Zheng L, Fei K, Zhou C, Manegold C and Bindert GC: ROS1 fusions in Chinese patients with non-small-cell lung cancer. Ann Oncol 24: 1822-1827, 2013. 
55. Takeuchi K, Soda M, Togashi Y, Suzuki R, Sakata S, Hatano S, Asaka R, Hamanaka W, Ninomiya $\mathrm{H}$, Uehara $\mathrm{H}$, et al: RET, ROS1 and ALK fusions in lung cancer. Nat Med 18: 378-381, 2012.

56. Bergethon K, Shaw AT, Ou SH, Katayama R, Lovly CM, McDonald NT, Massion PP, Siwak-Tapp S, Gonzalez A, Fang R, et al: ROS1 rearrangements define a unique molecular class of lung cancers. J Clin Oncol 30: 863-870, 2012.

57. Kohno T, Ichikawa H, Totoki Y, Yasuda K, Hiramoto M, Nammo T, Sakamoto H, Tsuta K, Furuta K, Shimada Y, et al: KIF5B-RET fusion in lung adenocarcinoma. Nat Med 18: 375-377, 2012.

58. Wang R, Hu H, Pan Y, Li Y, Ye T, Li C, Lou X, Wang L, Li H, Zhang Y, et al: RET fusions define a unique molecular and clinic pathologic subtype of non-small-cell lung cancer. J Clin Oncol 30: 4352-4359, 2012

59. Eng C: RET proto-oncogene in the development of human cancer. J Clin Oncol 17: 380-393, 1999.

60. Chao BH, Briesewitz R and Villalona-Calero MA: RET fusion genes in non-small-cell lung cancer. J Clin Oncol 30: 4439-4441, 2012.

61. Bodner SM, Minna JD, Jensen SM, D'Amico D, Carbone D Mitsudomi T,Fedorok J, Buchhagen DL, Nau MM and Gazdar AF: Expression of mutant p53 proteins in lung cancer correlates with the class of p53 gene mutation. Oncogene 7: 743-749, 1992.

62. Husgafvel-Pursiainen KH, Boffetta P, Kannio P, Nyberg F Pershagen G, Mukeria A, Constantinescu V, Fortes C and Benhmou S: P53 Mutations and exposure to environmental tobacco smoke in a multicenter study on lung cancer. Cancer Res 60: 2906-2911, 2000.

63. Tammemagi MC, McLaughlin JR and Bull SB: Meta-analyses of p53 tumor suppressor gene alterations and clinicopathological features in resected lung cancers. Cancer Epidemiol Biomark Prev 8: 625-634, 1999.

64. Yanaihara N, Caplen N, Bowman E, Seike M, Kumamoto K, Yi M, Stephens RM, Okamoto A, Yokota J, Tanaka T, et al: Unique microRNA profiles in lung cancer diagnosis and prognosis. Cancer Cell 9: 189-198, 2006.

65. Johnson SM, Grosshans H, Shingara J, Byrom M, Jarvis R Cheng A, Labourier E, Reinert KL, Brown D and Slack FJ: RAS is regulated by the let-7 microRNA family. Cell 120: 635-647, 2005.

66. Lee YS and Dutta A: The tumor suppressor microRNA let-7 represses the HMGA2 oncogene. Genes Dev 21: 1025-1030, 2007.

67. Weiss GJ, Bemis LT, Nakajima E, Sugita M, Birks DK, Robinson WA, Varella-Garcia M, Bunn PA Jr, Haney J, Helfrich BA, et al: EGFR regulation by microRNA in lung cancer: Correlation with clinical response and survival to gefitinib and EGFR expression in cell lines. Ann Oncol 19: 1053-1059, 2008.

68. He L, He X, Lim LP, Stanchina ED, Xuan Z, Liang Y, Xue W, Zender L, Magnus J, Ridzon D, et al: A microRNA component of the p53 tumor suppressor network. Nature 447: 1130-1134, 2007.

69. Antoniou AC, Casadei S, Heikkinen T, Barrowdale D, Pylkäs K Roberts J, Lee A, Subramanian D, De Leeneer K, Fostira F, et al: Breast-cancer risk in families with mutations in PALB2. N Engl J Med 371: 497-506, 2014.

70. Thompson ER, Rowley SM, Sawyer S, kConFab, Eccles DM, Trainer AH, Mitchell G, James PA and Campbell IG: Analysis of RAD51D in ovarian cancer patients and families with a history of ovarian or breast cancer. PloS One 8: e54772, 2013.

71. Imyanitov EN and Moiseyenko VM: Drug therapy for hereditary cancers. Hered Cancer Clin Pract 9: 5, 2011.

72. Li X and Hemminki K: Inherited predisposition to early onset lung cancer according to histological type. Int J Cancer 112: 451-457, 2004

73. Lindor NM, McMaster ML, Lindor CJ and Greene MH; National Cancer Institute, Division of Cancer Prevention, Community Oncology and Prevention Trials Research Group: Concise handbook of familial cancer susceptibility syndromes-second edition. J Natl Cancer Inst Monogr 38: 1-93, 2008.

74. Wells SA Jr, Gosnell JE, Gagel RF, Moley J, Pfister D, Sosa JA, Skinner M, Krebs A, Vasselli J and Schlumberger M: Vandetanib for the treatment of patients with locally advanced or metastatic hereditary medullary thyroid cancer. J Clin Oncol 28: 767-772, 2010.

75. Imyanitov EN and Byrski T: Systemic treatment for hereditary cancer: A 2012 update. Can Clin Pract 11: 2, 2013.

76. Narod SA: BRCA mutations in the management of breast cancer: The state of the art. Nat Rev Clin Oncol 7: 702-707, 2010.

77. Joosse SA, Brandwijk KI, Mulder L, Wesseling J, Hannemann J and Nederlof PM: Genomic signature of BRCA1 deficiency in sporadic basal-like breast tumors. Genes Chromosomes Cancer 50: 71-81, 2011
78. Half E, Bercovich D and Rozen P: Familial adenomatous polyposis. Orphanet J Rare Dis 4: 22, 2009.

79. Kennelly RP, Gryfe R and Winter DC: Familial colorectal cancer: Patient assessment, surveillance and surgical management. Eur J Surg Oncol: Jul 27, 2016 (Epub ahead of print).

80. Vilar E and Gruber SB: Microsatellite instability in colorectal cancer-the stable evidence. Nat Rev Clin Oncol 7: 153-162, 2010

81. Gaughan EM, Cryer SK, Yeap BY, Jackman DM and Costa DB Family history of lung cancer in never smokers with non-small cell lung cancer and its association with tumor harboring EGFR mutations. Lung Cancer 79: 193-197, 2013.

82. Liu P, Vikis HG, Wang D, Lu Y, Wang Y, Schwartz AG, Pinney SM, Yang P, de Andrade M, Petersen GM, et al: Familial aggregation of common sequence variants on 15q24-25.1 in lung cancer. J Natl Cancer Inst 100: 1326-1330, 2008

83. Wu AH, Fontham ET, Reynolds P, Greenberg RS, Buffler P, Liff J, Boyd P and Correa P: Family history of cancer and risk of lung cancer among lifetime non-smoking women in the United States. Am J Epidemiol 143: 535-542, 1996.

84. Bromen K, Pohlabeln H, Jahn I, Ahrens W and Jöckel KH Aggregation of lung cancer in families: Results from a population based case control study in Germany. Am J Epidemiol 152: 497-505, 2000

85. Hemminki K, Dong C and Vaittinen P: Cancer risks to spouses and offspring in the family-cancer database. Genet Epidemiol 20: 247-257, 2001

86. Hemminki K and Li X: Familial risk for lung cancer by histology and age of onset: Evidence for recessive inheritance. Exp Lung Res 31: 205-215, 2005.

87. Jonsson S, Thorsteinsdottir U, Gudbjartsson DF, Jonsson HH, Kristleifur K, Arnason S, Gudnason V, Isaksson HJ, Hallgrimsson J, Gulcher JR, et al: Familial risk of lung carcinoma in the icelandic population. JAMA 292: 2977-2983, 2004.

88. Jin T, Zhou X and He X: The general measurement of genetic factors on lung cancer in Xuanwei, China. Zhongguo Fei Ai Za Zhi 4: 354-356, 2001 (In Chinese).

89. Jin Y, Xu Y, Xu M and Xue S: Increased risk of cancer among relatives of patients with lung cancer in China. BMC Cancer 5: 146,2005

90. Socialstyrelsen: Cancer Incidence in Sweden 2000. http://www. socialstyrelsen.se/publikationer2002/2002-42-5. Accessed March 20, 2015.

91. Nitadori J, Inoue M, Iwasaki M, Otani T, Sasazuki S, Nagai K and Tsugane S: Association between lung cancer incidence and family history of lung cancer: Data from a large-scale population-based cohort study, the JPHC study. Chest 130: 968-975, 2006.

92. Coté ML, Kardia SL, Wenzlaff AS, Ruckdeschel JC and Schwartz AG: Risk of lung cancer among white and black relatives of individuals with early-onset lung cancer. JAMA 293: 3036-3042, 2005.

93. Osann KE: Lung cancer in women: The importance of smoking, family history of cancer and medical history of respiratory diseases. Cancer Res 51: 4893-4897, 1991.

94. Yu XJ, Yang MJ, Zhou B, Wang GZ, Huang YC, Wu LC, Cheng X, Wen ZS, Huang JY, Zhang YD, et al: Characterization of somatic mutations in air pollution-related lung cancer. EBioMedicine 2: 583-590, 2015

95. Spitz MR, Amos CI, Dong Q, Lin J and Wu X: The CHRNA5-A3 region on chromosome 15q24-25.1 is a risk factor both for nicotine dependence and for lung cancer. J Natl Cancer Inst 100: 1552-1556, 2008.

96. Hung RJ, McKay JD, Gaborieau V, Boffetta P, Hashibe M, Zaridze D, Mukeria A, Szeszenia-Dabrowska N, Lissowska J, Rudnai P, et al: A susceptibility locus for lung cancer maps to nicotinic acetylcholine receptor subunit genes on $15 \mathrm{q} 25$. Nature 452: 633-637, 2008.

97. You M, Wang D, Liu P, Vikis H, James M, Lu Y, Wang Y, Wang M, Chen Q, Jia D, et al: Fine mapping of chromosome 6q23-25 region in familial lung cancer families reveals RGS17 as a likely candidate gene. Clin Cancer Res 15: 2666-2674, 2009.

98. Bell DW, Gore I, Okimoto RA, Godin-Heymann N, Sordella R, Mulloy R, Sharma SV, Brannigan BW, Mohapatra G, Settleman J and Haber DA: Inherited susceptibility to lung cancer may be associated with the T790M drug resistance mutation in EGFR. Nat Genet 37: 1315-1316, 2005.

99. Oxnard GR, Miller VA, Robson ME, Azzoli CG, Pao W, Ladanyi $M$ and Arcila ME: Screening for germline EGFR T790M mutations through lung cancer genotyping. J Thorac Oncol 7: 1049-1052, 2012 . 